\title{
ARTEMISIA GENTILESCHI E OS MECENAS DE SEU TEMPO: CARTAS DE UMA PINTORA DO SÉCULO XVII
}

\author{
Resenha de: SOLINAS, Francesco. (Org.) Lettere di \\ Artemisia. Firenze: De Luca Editori d'Arte, 2011.
}

\section{Cristine Tedesco ${ }^{*}$}

A obra organizada por Francesco Solinas (2011), intitulada Lettere di Artemisia ${ }^{1}$, é uma edição crítica e anotada da correspondência da pintora italiana Artemisia Gentileschi (15931654). A publicação inclui mais de 35 cartas inéditas da correspondência profissional e amorosa e outros documentos, assinados por Artemisia e seu marido Pierantonio Stiattesi, relativos ao período florentino e ao retorno da pintora à Roma, em 1620. A publicação inclui ainda todas as cartas de Artemisia já editadas, entre elas a correspondência escrita de Nápoles ao mecenas Cassiano dal Pozzo, erudito e colecionador de arte, residente em Roma; ao aristocrata e mecenas don Antônio Ruffo; bem como as cartas ao Grão Duque Cosimo II de Medici e Ferdinando II de Medici; ao ministro Andrea Cioli; a Galileu Galilei e ao Duque Francesco I d'Este. Além das contribuições críticas e comentários de Francesco

* Doutoranda em História na Universidade Federal do Rio Grande do Sul.

1 Francesco Solinas é historiador da arte e crítico de arte especialista no período entre a Renascença e o Antigo Regime. Desenvolve estudos sobre a relação entre arte, criação artística, política e diplomacia a partir de correspondências. Atualmente é professor conferencista na Collège de France. A publicação Lettere de Artemisia reúne um total de 71 cartas enviadas e recebidas por Artemisia entre 1619 a 1651, não incluindo imagens da pintora. As correspondências estão localizadas nos seguintes acervos italianos: Archivio di Stato di Firenze (ASF), Archivio Storico Frescobaldi e Albizzi (ASFA), Biblioteca Nazionale di Firenze (BNF), Archivio di Stato di Modena Archivio Segreto Estente (ASM ASE), Archivio Storico del Banco di Napoli (ASBN). 
Solinas, a edição Lettere di Artemisia ainda conta com a colaboração de Michele Nicolaci e Yuri Primarosa.

Algumas questões iniciais são importantes para situar Artemisia Gentileschi em seu contexto. Filha primogênita e única mulher entre os quatro filhos do pintor Orazio Gentileschi e de sua esposa Prudenza Montore, Artemisia nasceu em Roma, em julho de 1593. Órfã de mãe aos 12 anos, conheceu e aprendeu com o pai a arte da pintura. Realizou funções de aprendiz, como moer pigmentos e preparar cores e fundos paras as telas, além de desenhar figuras humanas e colaborar amplamente com as obras de Orazio Gentileschi. Ainda que Artemisia tenha atuado para a família Medici e para a coroa inglesa, a pintora produziu com muito mais frequência para um público amplo de mecenas, patronos e colecionadores particulares.

Notamos que Artemisia construiu uma autonomia maior que outras pintoras, a exemplo de Sofonisba Anguissola, Elisabeta Sirani e Lavinia Fontana, provavelmente porque se desvinculou do pai ainda jovem, quando partiu para Florença, passando a viver da pintura sem uma figura masculina à sua frente, como revela sua correspondência e outras fontes como recibos de pagamentos de suas obras e inventários. Uma vida longa consolidou Artemisia Gentileschi na arte; ela viveu mais de 60 anos e produziu para algumas das cortes mais importantes de seu tempo ${ }^{2}$.

No prefácio da publicação Francesco Solinas (2011) apresenta uma breve revisão bibliográfica apontando os principais trabalhos desenvolvidos sobre a pintora Artemisia Gentileschi entre os séculos XX e XXI. De acordo com o autor, entre os artistas do período Barroco, cujas vida e obra têm suscitado um profundo interesse do público da última parte do século $\mathrm{XX}$, podemos certamente encontrar Artemisia Gentileschi. Contudo, Solinas (2011) pondera que, em relação ao "maldito" Caravaggio, ao "diplomático" Rubens e ao "político" Bernini, ou mesmo considerando outros artistas como Van Dyck, Poussin e Rembrandt, Artemisia aparece como menos qualificada, sua obra foi vista como modesta e exígua.

2 Para saber mais é possível consultar: TEDESCO, Cristine. "E non dite che dipingeva come un uото”: história e linguagem pictórica de Artemisia Lomi Gentileschi entre as décadas de 1610 e 1620 em Roma e Florença. 2013. 193f. Dissertação (Mestrado) - Programa de PósGraduação em História. Universidade Federal de Pelotas. 
Assim, há ainda hoje muito o que perguntar sobre essa pintora e sua personalidade, que a coloca entre as mais fascinantes e modernas, e sua vida entre as mais aventureiras daqueles tempos, como destaca Solinas (2011, p. 7). De acordo com o mesmo autor, a partir de estudos recentes sobre sua trajetória e suas criações pictóricas, Artemisia vem recuperando a posição de extrema relevância que ocupou durante sua vida.

Nesse sentido, é importante lembrar que Artemisia atuou em cidades importantes para a época, como Roma, Florença, Veneza, Nápoles e Londres, onde colaborou numa obra iniciada pelo pai a pedido da família Stuart. Sua produção não restringiu-se aos temas do universo privado e retratos, mais comuns na produção de mulheres pintoras daquele período. Artemisia explorou os temas do Barroco, inclusive nus e foi a primeira mulher aceita na Academia de Belas Artes de Florença, o que lhe permitiu ter seu próprio atelier e contratar modelos. Foi reconhecida por seus pares, homenageada por literatos venezianos que lhe dedicaram diversos poemas e sua trajetória artística foi registrada pelos biógrafos da época e posteriores. Além disso, a pintora também contribuiu com o grupo de artistas empenhados em tornar a pintura, até então considerada um ofício mecânico, uma atividade intelectual quando produziu sua obraprima, a Alegoria da Pintura (1638-1639) para a família real inglesa.

Conforme Solinas (2011), durante o século XIX Artemisia ficou esquecida, assim como o ficaram seu trabalho como pintora e a experiência que adquiriu nos mais diversos ambientes artísticos que frequentou na Europa. Muitas de suas obras, apreciadas entre os maiores colecionadores de seu tempo, foram localizadas e reconhecidas recentemente, mais de um século depois da publicação do processo crime intitulado Stupri et Lenocinij Pro Curia et Fisco, organizado por Antonino Bertolotti (1876) $)^{3}$. A publicação dos documentos do processo penal contra o pintor Agostino Tassi, acusado de estuprar a jovem pintora, repercutiu sobre sua vida em Roma. Artemisia foi lembrada somente pela ótica do escândalo 
público que o processo significou, o que não trouxe reconhecimento à sua pintura, a qual ainda hoje é conhecida apenas parcialmente.

Entre as décadas de 1960 e 1990, duas publicações importantes sobre Artemisia apareceram nos Estados Unidos. Ward Bissell (1968) e Mary Garrard (1989) iniciaram uma reconstituição biográfica e trabalharam com sua obra pictórica, inaugurando uma nova perspectiva sobre Artemisia Lomi Gentileschi, que até então havia sido lembrada na pintura como mera discípula do pai. Francesco Solinas destaca ainda o primeiro catálogo ${ }^{4}$ sobre Artemisia do qual temos conhecimento. Publicado em 1991, foi o resultado da exposição realizada na Casa Buonarroti, na cidade de Florença. No catálogo de 1991, há a contribuição dos pesquisadores Luciano Berti, Pina Ragionieri, Giuseppe Bartolomei, além dos textos dos organizadores, Roberto Contini e Gianni Papi. Ao longo dos artigos, existe uma tendência em mostrar uma Artemisia diferente daquela apresentada como aprendiz do pai e seguidora de Caravaggio.

Por fim, Solinas menciona os trabalhos de Keith Christiansen e Judith Mann $(2001)^{5}$ como as últimas reflexões sobre a técnica pictórica de Artemisia. O mesmo autor não deixa de lembrar suas próprias contribuições aos estudos que tratam da vida e obra de Artemisia na exposição ${ }^{6}$ realizada em Milão, em 2011, no mesmo ano da publicação de Lettere di Artemisia. Solinas (2011, p. 9) finaliza a primeira parte do prefácio afirmando que Artemisia estudou modelos, reinventou modos de reproduzir a luz em suas obras, produziu com a intensidade dos mais importantes artistas das cidades nas quais viveu.

A publicação também apresenta um texto de caráter biográfico sobre a trajetória de Artemisia. Entre os artistas da família de Artemisia estão o pai Orazio Gentileschi, um pintor maneirista da região da Toscana que se estabeleceu em Roma, onde conheceu e adotou o caravaggismo; e o tio, Aurelio Lomi, que se estabeleceu em Florença e atuou como pintor, principalmente para a corte dos

4 CONTINI, Roberto; PAPI, Giami (Org.). Artemisia. Catalogo della mostra. Leonardo de Luca: Firenze, 1991.

5 CHRISTIANSEN, Keith; MANN, Judith W. Orazio and Artemisia Gentileschi: Father and Daighter Painters in Baroque Italy. New York: The Metropolitan Museum of Art, 2001.

6 CONTINI, Roberto; SOLINAS, Francesco. (Org.). Artemisia Gentileschi. Storia di una passione. Milano: 24 ORE Cultura, 2011. 
Medici. Após a conclusão do processo crime, em 1612, e a realização do matrimônio com Pierantonio Stiattesi Artemisia se estabeleceu com o marido em Florença, provavelmente fugindo da situação que se criou em torno da pintora em Roma. Na cidade florentina, Artemisia passou a ter visibilidade através de sua pintura, e produziu obras encomendadas principalmente pela família Medici.

Esse período foi um dos mais importantes para a trajetória de Artemisia, porque foi em Florença que conheceu intelectuais de seu tempo, poetas, músicos, escritores e eruditos, com os quais se correspondeu posteriormente, a exemplo de Galileu Galilei. A saída repentina de Artemisia de Florença para Roma, em 1620, se deu devido a questões financeiras. O acúmulo de dívidas decorrente de um contrato de trabalho mal pago pelo Grão-Duque Cosme II, que se encontrava muito doente e debilitado devido à tuberculose, trouxe problemas econômicos e sua situação em Florença ficou insustentável (SOLINAS, 2011, p. 79).

Em Roma, Artemisia passou a receber frequentes encomendas de cardeais e jovens mulheres de famílias nobres, que a procuravam para encomendar retratos, afirma Francesco Solinas (2011). O historiador da arte ressalta que para dar conta da intensa rotina de trabalho no ateliê, Artemisia contratou assistentes que lhe preparavam as telas e as cores, como foi o caso de Alessandro Bardelli (SOLINAS, 2011, p. 88). Em solo romano, Artemisia foi admirada por outros artistas de seu tempo, como Pierre Dumonstier, Simon Vouet e Jérôme David, cujos quais produziram obras em sua homenagem. O mesmo autor lembra que o reconhecimento internacional da pintora criou condições para sua saída da Península Itálica, em 1638, com destino a Londres, onde colaborou com seu pai na produção de uma obra para o teto da Casa da Rainha (Queen's House de Inigo Jones) em Greenwich, realizada antes da morte de Orazio Gentileschi, em 1639. A temporada em Londres acabou sendo muito positiva, e ao retornar a Nápoles, entre 1640 e 1641, sua fama internacional rendeu-lhe um período de grande crescimento nas encomendas e reconhecimento entre mecenas, governadores, duques e duquesas de diferentes regiões.

$\mathrm{Na}$ correspondência de Cassiano dal Pozzo é possível encontrar seis cartas enviadas ao colecionador por Artemisia Gentileschi entre 1630 e 1637 . O célebre erudito e amante da arte 
integrou o grupo de conselheiros de Francesco Barberini - um dos responsáveis pelo desenvolvimento da vida artística romana do período, conforme Francis Haskell (1997) ${ }^{7}$. Na carta de 24 de agosto de 1630, por exemplo, Artemisia informou a dal Pozzo que ao finalizar alguns quadros para a Imperatriz seu primeiro compromisso seria "[...] servire Vostra Signoria Illustrissima, alla quale tanto devo" . Fez questão de mencionar os quadros que estava produzindo para a Imperatriz também como uma forma de se apresentar como uma pintora que atuava entre grupos ilustres. Na mesma carta Artemisia solicitou o envio de "[...] sei para di guanti delle più belli che io ne ho da regalare alcune dame", , reforçando ao patrono sua presença num contexto respeitável. De acordo com Solinas (2011, p. $85)$, as luvas romanas estavam entre as mais prestigiadas do período e muitas vezes eram oferecidas como presentes diplomáticos por cardeais e núncios papais. Essas questões aludem aos ambientes nos quais Artemisia circulava em seu cotidiano como pintora e a rede de relações da qual fazia parte.

Em 9 de outubro de $1635^{10}$ Artemisia escreveu a Galileu Galilei, que já estava no exílio em Arcetri, nos arredores de Florença, pedindo-lhe para intervir em seu nome com o Grão-duque Ferdinando II sobre os dois quadros que ela tinha enviado. Artemisia não tinha recebido nenhuma resposta do Grão-duque sobre as pinturas, e muito menos uma doação ou pagamento. A pintora fez amistosa referência à ajuda que o cientista lhe deu no passado a respeito de um retrato de Judite, produzido para Cosme II. Ela fez uma comparação entre o silêncio do Grão-duque e a generosidade de outros soberanos com ela. Também mencionou as honras e recompensas que ela tinha recebido dos líderes mais poderosos da Europa. Provavelmente Artemisia enfrentava problemas econômicos nesse período, visto que está escrevendo a Galileu pedindo sua intervenção no sentido de receber alguma remuneração do Grão-duque pelos quadros enviados.

7 HASKELL, Francis. Mecenas e pintores: arte e sociedade na Itália barroca. São Paulo: Edusp, 1997.

8 "Servir Vossa Senhoria Ilustríssima, à qual tanto devo". Lettere di Artemisia, 2011, p. 85. Tradução livre.

9 "Seis pares de luvas das mais belas que eu preciso para presentear algumas damas". Ibid., p. 85. Tradução livre.

10 Ibid., p. 109-110. 
Os embates da pintora frente às questões de gênero e as relação de poder de seu tempo tornam-se mais evidentes em alguns fragmentos de suas correspondência, a exemplo de quando respondeu a um pedido de envio de esboço de uma tela encomendada pelo nobre siciliano don Antônio Ruffo, em janeiro de 1649, [...] "il nome di donna fa star sempre in dubbio sinché non si è visto l'opra"11. A pintora não apenas negociava as imagens, como também buscava valorizar seu próprio trabalho, não aceitando propostas que diminuíssem valores por motivos de atraso nas entregas. Essa questão pode ser notada numa correspondência enviada a Ruffo, em agosto de 1649 quando a pintora justificou o atraso de entrega de um quadro e finalizou dizendo: "[...] farò vedere a Vostra Signoria Illustrissima quello che sa fare una donna"12. Em outubro do mesmo ano Artemisia respondeu ao aviso de Ruffo de que diminuiria o valor do pagamento devido a um novo atraso. A pintora apontou com orgulho suas origens romanas, dizendo: "Avverta V. S. Ill.mo che quando io domano um prezo non fo all'usanza di Napoli che domandano trenta e po'danno per quatro [...] io so' romana e perciò voglio procedere sempre alla romana $^{13}$. Ao final da correspondência ressaltou: "Vostra Signoria Illustrissima non perderà con me e ritroverà uno animo di Cesare nell'anima di una donna"14. Artemisia valoriza o gosto de seu patrono, mas também enfatiza suas origens romanas, provavelmente buscando transmitir seu comprometimento com a produção da obra. Artemisia ainda mencionou sua atuação em outras regiões da Península Itálica provavelmente como uma maneira de agregar valor às suas obras e também como forma de mostrar seu reconhecimento, se construindo como pintora experiente e prestigiada. Acreditamos que Artemisia tanto desestabiliza o contexto no qual está inserida,

11 "O nome da mulher cria sempre uma dúvida até que não se veja a obra". Ibid., p. 126. Tradução livre.

12 "Mostrarei para Vossa Senhoria Ilustríssima aquilo que uma mulher sabe fazer". Ibid., p. 130. Tradução livre.

13 "Considere Vossa Senhoria Ilustríssima que quando eu peço um preço não faço ao modo de Nápoles que pedem trinta e depois dão por quatro [...] eu sou romana, e por isso quero proceder sempre ao modo romano". Ibid., p. 134. Tradução livre.

14 "Encontrará uma força de César na alma de uma mulher". Ibid., p. 133. Tradução livre. 
como também revela ambiguidades e principalmente negocia com os limites de seu tempo quando se constrói como mulher pintora.

A correspondência de Artemisia permite investigar a rede de relações construída pela pintora nas cortes e instituições nas quais atuou na primeira metade do século XVII, problematizando as relações e representações de gênero e a cultura do período entre os séculos XVI e XVII. Nesse sentido, a publicação contribui em especial com as discussões sobre como Artemisia se inseriu e atuou no mundo da produção artística, ainda que a conjuntura histórica da época dificultasse $\mathrm{o}$ acesso à cultura letrada, às técnicas e ao conhecimento em geral.

Lembramos que a trajetória de Artemisia Gentileschi foi construída pela historiografia da arte a partir do texto de Roberto Longhi, Gentileschi. Padre e Figlia (1916/2011) ${ }^{15}$. A tendência dos autores que o sucederam foi explicar a trajetória de Artemisia como consequência da profissão do pai e apresentar sua obra como reprodução do conceito de chiaro-scuro explorado por Michelangelo Merisi, o Caravaggio. Nas últimas décadas do século XX a obra da artista foi convertida em uma espécie de vingança contra seu estuprador, Agostino Tassi. Nesse sentido, em nossas pesquisas sobre Artemisia Gentileschi, procuramos ultrapassar anacronismos e chavões que muitas vezes simplificaram a importância de sua obra, principalmente porque episódios específicos de sua trajetória biográfica foram considerados chaves de leitura para explicar sua produção, a exemplo do estupro do qual foi vítima em Roma, em 1611.

As recentes radiografias de obras da $\operatorname{artista~}^{16}$, apontam que a pintora desenvolveu uma linguagem permeável aos diferentes contextos nos quais atuou. Artemisia possuía a capacidade de adaptarse às exigências das cortes da Península Itálica e da Europa. Seus estudos de perspectiva, de claro-escuro e de anatomia, além da valorização que dava às suas próprias criações, de sua busca

15 LONGHI, Roberto. Gentileschi. Padre e figlia. Carte d'artisti. Milano: Abscondita, 2011. 16 Ver a publicação do catálogo da Mostra Artemisia, realizada em Roma, entre dezembro de 2016 e maio de 2017: SPINOSA, Nicola; BALDASSARI, Francesca; MANN, Judith. (Org.). Artemisia Gentileschi e il suo tempo. Catalogo della mostra. Museo di Roma. Milano: Arthemisia Group, Skira editore, 2016. 
incansável em ser uma pintora em constante diálogo com os artistas de seu tempo e sua inserção em diferentes contextos advertem que não podemos reduzir a arte à autobiografia, como se a pintura de Artemisia fosse resultado direto das experiências que viveu.

RECEBIDA EM: 04/07/2016 APROVADA EM: 19/06/2017 